\title{
Cultivated Land Area Change in Shenzhen and Its Socio-Economic Driving Forces Based on STIRPAT Model
}

\author{
Li Shenghui ${ }^{1} \&$ Yin $\mathrm{Qi}^{2}$ \\ ${ }^{1}$ Sichuan Agriculture University, Chengdu, Sichuan, China \\ ${ }^{2}$ School of Economics and management, Sichuan Agriculture University, Chengdu, Sichuan, China \\ Correspondence: Li Shenghui, Sichuan Agriculture University, Chengdu, Sichuan, China. Tel: 86-156-8077-5239. \\ E-mail: li.shenghui1989@163.com
}

Received: April 17, 2012 Accepted: June 5, 2012 Online Published: June 28, 2012

doi:10.5539/jsd.v5n7p149 URL: http://dx.doi.org/10.5539/jsd.v5n7p149

\begin{abstract}
The purpose of this paper is to analyze the relationship between prosperous level and cultivated land area were analyzed in Shenzhen city, Method of the STIRPAT model. The results showed that there was no main cause for cultivated land reduction in Guangzhou city (Zhang, 1999). However, population change, changes of the urbanization rate and proportion of the tertiary-industry added value to regional GDP of the area all play important role in the cultivated land reduction. In the scope of observational data, the relationship between the prosperous level and the cultivated land area was not similar to the environmental kuznets curve (EKC). Accordingly, several suggestions were proposed in the study to mitigate the pressure of cultivated land reduction, including population control, urbanization level improvement, industrial structure adjustment, and economic growth mode transition, etc. (Cai \& Zhang, 2005).
\end{abstract}

Keywords: cultivated land area change, socio-economic driving forces, STIRPAT model, Shenzhen city

\section{Introduction}

Land use and land cover, the most significant landscape of the earth surface system, are restricted and affected by natural and human driving force. In terms of the shorter timescale, human driving force plays a dominant role in change of the land use, especially in the process of accelabrating urbanization in recent years. Rapid growth of the economy and big increase in the number of urban population formed a high demand for industrial sites, residential housing and public areas, which essentially leaded to an increasingly sharper contradiction between arable land protection and the augment of urban construction sites. Therefore, analysing human driving force in the quantity of arable land has a very important significant in predicting cultivated land demand in the condition of urbanization and establishing corresponding policies and measures. The research in the mechanism of driving forces for change in the cultivated land areas has attracted great attentions of many researchers, especially the research in the quantification and modeling of the driving forces (Zhao, 2006).

Some researchers studies the driving factors for conversion in farmland with the method of principal component analysis, replacing previous more variables by fewer new information(keeping the original information as much as possible, in order to reveal the dominant driving force for conversion in farmland. A mathematics analysis is presented on artificial factors of conversion in farmland and space variability with the method of land statistics by other researchers (Su WeizhongYang \& Gu Chaolin, 2007). In recent years, the STIRPAT model, which is in the environment research field, has been introduced into the studying of driving forces in cultivated land change. Some researchers have discussed and analysed it from the theory and demonstration aspect, seldom related researches have been released yet. This essay tries to use STIRPAT model, and discusses how socioeconomic factors, such as population, rich extent, industrial structure and urbanization level, affect the cultivated land change in rapid urbanization city, Shenzhen with its open policy (Yang, 2001; 2002; 2004).

\section{STIRPAT Model Summary}

STIRPAT model inherits from IPAT equation about environmental stress (Chertow, 2000). IPAT equation have been got different types of reconstruct or extend in practical applications. And Rose and Dietz expressed IPAT equation as random form, which analysis the driving force's effect to the environment by stochastic regression of population, affluence and technology, simply called STIRPAT model the forms are as follows: 


$$
I=a P^{b} A^{c} T^{d} e
$$

I, P, A, T Respectively Represents environmental stress, the number of population, affluence and technology (York et al., 2003). And the total energy consumption denote environmental pressures. A is the coefficient of the model, $b, c, d$ are the number of population, affluence and technology index of human driving forces, e-model errors. IPAT model is a special form of STRIPAT model, namely $\mathrm{a}=\mathrm{b}=\mathrm{c}=\mathrm{d}=\mathrm{e}=1$. STRIPAT models that retain relationships of the multiply among human driving forces in the IPAT model, and human driving force such as population, affluence and technology etc use as the main factors influencing the environmental pressure changes (Kang-Lin, 2006). The model is a non-linear model of multi-variable, after the model of the logarithm on both sides at the same time, changes to:

$$
\ln I=\ln a+b(\ln P)+c(\ln A)+d(\ln T)+\ln e
$$

$\operatorname{lnI}$ as an dependent variable, $\ln \mathrm{P}, \ln \mathrm{A}, \ln \mathrm{T}$ as arguments, $\operatorname{lna}$ as a constant, lne as a error. Multivariate linear fitting after processing model. Based on the concept of elasticity, $1 \%$ change in $\mathrm{p}$, a, $\mathrm{t}$, respectively, cause I changes by $\mathrm{b} \%, \mathrm{c} \%$ or $\mathrm{d} \%$. In order to study with the rich increase, whether between prosperity and environmental pressures will exist relationship of the "u" type of environmental Kuznets curve or not. Articles will put $\ln \mathrm{A}$ arguments in models (2) break up into $\ln \mathrm{A}$ and $(\ln \mathrm{A}) 2$.

$$
\ln I=f+b(\ln P)+c_{1}(\ln A)+c_{2}\left(\ln ^{2} A\right)+d(\ln T)+g
$$

According to the concept of elasticity coefficient, if the model (3) first-order partial derivatives are seeking lnA, can get elasticity coefficient of rich to pressures on the environment (EEIA).

$$
E E I A=c_{1}+2 c_{2} \ln A
$$

Known values of $\ln \mathrm{A}$, values of the EEIA can be calculated under the formula (4), If $\mathrm{C}_{2}$ is negative, you can determine there exist the environmental Kuznets curve and a rich State value of environment improvement (Zhou, 2003).

Application of STIRPAT model and elastic coefficients to address change on how to test the driving force in the empirical analysis on the impact of environmental change in Empirical analysis. Therefore, STIRPAT is better applied to the study of environmental pressure. York, who found that Elasticity ratio of population pressure on the environment which are expressed by $\mathrm{CO}_{2}$ emissions and energy footprint is close to 1; elastic coefficients of Per capita GDP growth on the characterization of environmental pressures of energy footprint is less than 1 and greater than 0 , that is, growth in per capita GDP per $1 \%$, environmental pressures up, but not more than $1 \%$ (York et al. 2003), total energy consumption and pollution from energy consumption were respectively adopt in a measure of environmental pressure indicators by Wang Limeng etc, STIRPAT models, time series data of China's total energy consumption, for example 1952-2003, analysis of human driving forces such as population, affluence, energy intensity and energy consumption of selected effects on the environment pressure (Vanci \& Zhao, 2001).

\section{The Analysis of the Cultivated Land Area Change and Its Socio-Economic Driving Forces Based on STIRPAT Model in Shenzhen City}

\subsection{An Overview of the Researched Area}

Shenzhen is one of the oldest special economic zones which develops from a deserted border town into a prosperous modern city and creates the "speedy Shenzhen" model with distinctive characteristics of the times. Almost from scratch, the GDP of Shenzhen has made a breakthrough to $7800 * 108$ yuan in a span of 30 years from 1979 to 2008 . The permanent population has soared from $33 * 104$ to $846 * 104$, representing an average annual increase of 12.82 percent.

In 2008 , Shenzhen has fully realized the integration of the urban and the rural. Only $0.1 \%$ in the primary industry and almost external transient population in agriculture have made this city an unique zone without countryside administration or agricultural accounts. However, behind the prosperous growth of the society and economics, the cultivated land area has decreased from $30000 \mathrm{hm}^{2}$ to $3000 \mathrm{hm}^{2}$, which indicates that the fall reaches more than $90 \%$.

Shenzhen is chose as the research area because it is a typical fast-urbanizing region. The change in the number of cultivated land area is obviously driven by the social factors. Besides, the change in the number of cultivated land area is hardly influenced by natural disasters or ecological restoration. There is little interfering factors when analyzing the model. 


\subsection{Index Selection and the Resource of Data}

\subsubsection{The Index Influenced by Environment}

The feature of the pressure of environment is often indicated by different indexes: York uses $\mathrm{CO}_{2}$ emission and energy footprint for the pressure of environment, Wang Limeng chooses the total energy consumption and the pollution produced by energy consumption, Xu Zhongmin employs ecological footprint (Xu \& Cheng, 2005).

His passage refers to the index of some related research which applies the change in cultivated land to describe the degree of the pressure of environment. The change in cultivated land associates with so many environmental problems including soil loss, desertification, soil degradation, industrial and mineral pollution and domestic pollution that lead to the extended soil loss area and the degradation of the quality of the cultivated land. Furthermore, more land for construction is needed because of the development in the city. A dense population and changes in structure of industry have altered the original situation of land utilization and the structure of energy. And the overcommit of energy is an important cause of environmental pollution (Floating Chen \& Chen Gang, 2001).

All in all, it is appropriate to use the cultivated land change as the index for the pressure of environment. Because it includes ecological factors, as well as environmental factors.

The data of cultivated land this passage uses from 1979 to 2008 comes from Shenzhen Statistic Almanac of recent years.

\subsubsection{Population and the Degree of Richness}

The index of the degree of richness is often indicated by annual per capita gross, so does this passage. Considering the influence of price index, this passage adopts the unified price of the annual per capital gross in 2008. The population index refers to the number of permanent residents in recent years in Shenzhen. The data is provided by Shenzhen Statistic Almanac of the research year.

\subsubsection{The Technology Index}

The technology index consists of structural index and modern index.

The structural index is also called industrial structure index. The adjustment of industrial structure can change the influence to environment caused by human being. The important driving factor for the fall of cultivated land is that the economic structure begins transforming from agriculture to manufacturing and service industry. The model in this passage chooses the tertiary industry in proportion to the local GDP as the index to reflex the industrial structure.

According to the modern theory, development or modernization will alleviate environmental problems, not cause the degradation of the current environment. Urbanization rate which is employed to reflect the degree of modernization by modern theorists relates to many modern systems. The degree of modernization (the permanent non-agricultural population in proportion to the whole permanent population) is used to indicate the degree of modernization. The data is provided by Shenzhen Statistic Almanac of the research year.

What's more, due to the random form of the STIRPAT, during the research, logarithmic quadratic term of the annual per capita gross is added to the argument. This can test whether the environmental Kuznets curve exists between cultivated land change and economic development.

\subsection{The Results of the Model and Analysis of It}

\subsubsection{The Results of the Model}

Article by least squares analysis in data in the model, With a minimum 2 multiplications for regression analysis in general need to resolve the data of the different parties and a variety of differential of linear two issues. Articles in STIRPAT model is the raw data to be a logarithmic transformation, Error reflects a relative error, and tend to have the same relative error of variance, It is therefore a STIRPAT model itself can be a better solution model, the heteroscedastic. Multicollinearity problems, first of all, the author of regional GDP per capita between logarithmic and quadratic correlation analysis, found the two correlation coefficients only as 0.618 , among other indicators have not been found on a linear. In the article by the front-line (2) and (3) in the model are called STIRPAT I Models and Model II. Use the model I and model II, use of Excel software 6SQ statistics modules in a regression analysis of the data and confidence level of $95 \%$ in, respectively, conclude that 2 of model parameters. See Table 1. 
Table 1. STIRPAT model estimation of cultivated land change in Shenzhen city

\begin{tabular}{|c|c|c|c|c|c|c|}
\hline & \multicolumn{3}{|c|}{ Model A } & \multicolumn{3}{|c|}{ Model B } \\
\hline & Factor & $\begin{array}{l}\text { T inspection } \\
\text { value }\end{array}$ & Significant & Factor & $\begin{array}{l}\text { T inspection } \\
\text { value }\end{array}$ & Significant \\
\hline The constant term & 11.90549 & 2.349489 & Significant & 8.9749 & 2.7761 & Significant \\
\hline Total population (P1) & -0.36384 & -0.8374 & $\begin{array}{c}\text { Not } \\
\text { significant }\end{array}$ & -1.03286 & -1.9141 & Significant \\
\hline GDP per capita (A1) & 0.155924 & 0.46666 & $\begin{array}{c}\text { Not } \\
\text { significant }\end{array}$ & 2.6511 & 5.1418 & Significant \\
\hline $\begin{array}{l}\text { Gross proportion of } \\
\text { tertiary industry }(\mathrm{T} 1)\end{array}$ & 1.82507 & 1.30505 & Significant & 1.9590 & 2.6485 & Significant \\
\hline Urbanization rate (T2) & -2.23163 & -1.54589 & $\begin{array}{c}\text { Not } \\
\text { significant }\end{array}$ & -4.2257 & -3.4659 & Significant \\
\hline $\begin{array}{l}\text { Per capita GDP for the } \\
\text { second time (A12) }\end{array}$ & & & & -0.8438 & -4.5259 & Significant \\
\hline Adjusted R2 & 0.6382 & & & 0.88 & & \\
\hline F statistics & 8.9397 & & & 27.40384 & & \\
\hline Dubin-Watson statistic & 0.4175 & & & 1.82 & & \\
\hline
\end{tabular}

Discription: We can find the goodness of fit is $63.82 \%$ in Table 1, the coefficients of total population, per capita GDP and urbanization rate cannot pass $t$ test, which declares that the fitting efficiency is not so good, while it reaches $88 \%$ in Table 2 and the index coefficient which have been chose are all at 0.05 , obviously upon 0 , and the fitting equation is good, showing that model 2 can illustrate the relationship between the vary of dimension in Shenzhen and social economic development.

The concrete form of model 2 is

$$
\ln (\mathrm{I})=8.9749-1.914(\ln \mathrm{P})+2.6511(\ln \mathrm{A})+1.9590(\ln \mathrm{T} 1)-4.2257(\ln \mathrm{T} 2)-0.8438 \ln ^{2}(\mathrm{~A})
$$

In formula (5), I--agricultural acreage, $104 \mathrm{hm}^{2}$ : P--permanent residence, million; A-- per capita GDP, yuan/person; T1-- industrial structure index, \%; T2-- Modernization Index, i.e. urbanization rate, \%.

\subsubsection{Analyze}

Analyzing each index coefficient in model 2, it can be inferred that the change of permanent resident population in Shenzhen has a distinct impact on the increase and decrease of agriculture acreage dimension. The increase of total population affects the decrease of agriculture acreage. In the situation which shares the same other conditions, $1 \%$ increase of total population result in $1.9194 \%$ decrease of agriculture acreage dimension. All of the above shows that the change of population influences largely on the decrease of agriculture acreage during the rapid economic developing period.

The tertiary industry share of GDP accounts for each additional 1\% will result in an increase of 1.9590 percent of arable land, which shows the development of tertiary industry promotes the intensification of the regional land use extent, and slows down the process of land conversion. This is consistent with the Development Strategy of Shenzhen City's industrial adjustment. The related research also shows that the economic development in Shenzhen gradually becomes intensive from the extensive.

The increase of urbanization rate will reduce arable land, increase 1 percent rate of urbanization will make arable land decreased by $4.2257 \%$, this is contradict with the improvement of hypothetical urbanization level can make intensive use of land extent and the decrease of the conversion of arable land, but facing to the specific circumstances of Shenzhen, in the process of rapid development of city, it's necessary to occupy cultivated land appropriately, the key is to make a reasonable plan to take full advantage of a good share of arable land resources, and at the same time to further strengthen the intensive use of urban land.

The quadratic coefficient of Per capita GDP is negative. From this it can be seen that cultivated land change in Shenzhen City, in theory, may be similar to the environmental Kuznets curve, but it is in the curve, needs further 
examination.

Take (5) evaluating the lnA first-order partial derivatives EEIA, get per capita GDP - the coefficient of elasticity (EEIA) of rich degree's impact to arable land is 2.6511-1.6876 lnA. When percapita GDP values are made differently, to calculate the coefficient of elasticity and calculate the observed changes of the data within the coefficient of elasticity of the adjacent years, the results shown in Figure 1.

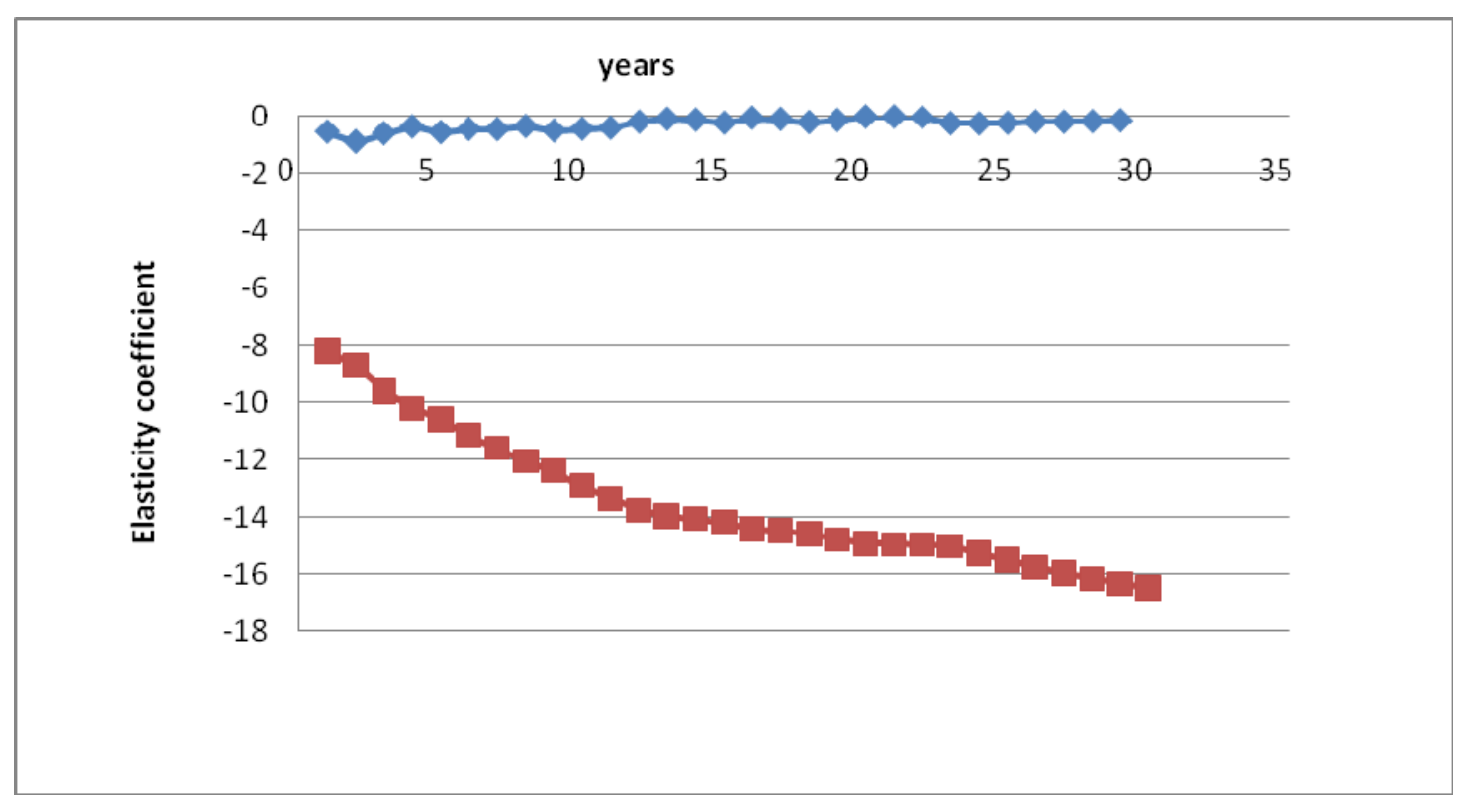

Figure 1. Different year GDP per capita in the area of agricultural land affected the elasticity coefficient

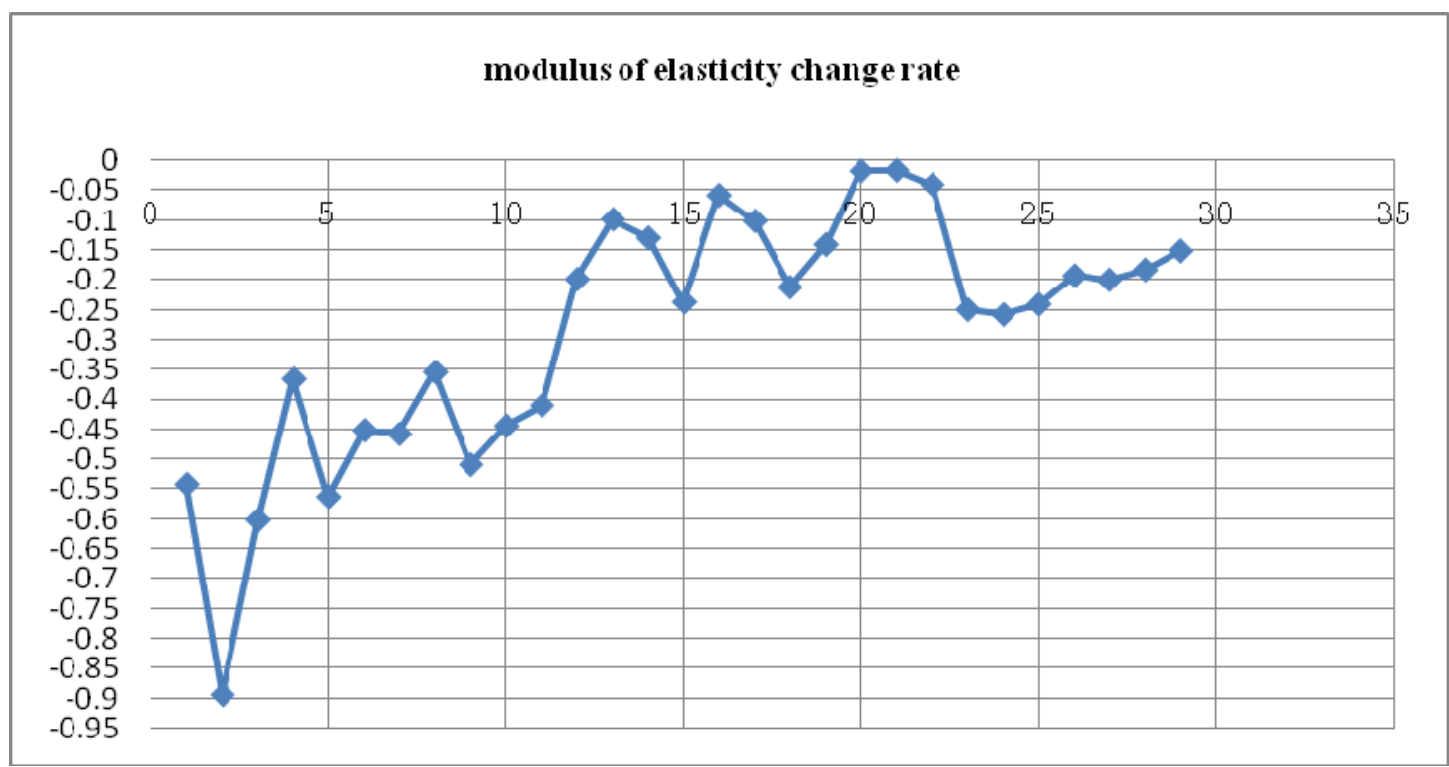

Figure 2. Modulus of elasticity change rate

Description: From the Picture 1, the Elasticity Coefficient of wealth grade effect on the cultivated land is negative. In conclusion, in the researched area, the growth of the GDP promotes the drop of the cultivated land. As years go by, the promotion becomes strongly. It fits the development situation since the reforming and opening. The rapid development drives non-ruralization.

At the beginning of the reforming and opening, the Elasticity Coefficient fluctuates greatly, especially in 1992. Because this year's urbanizing level jumps from $64 \%$ in 1991 to $72 \%$. Limited by the number of the cultivated 
land, the city averts from extending outward to explore the potential area. The speed of the loss of the cultivated land becomes slowly or stagnant, just like a straight line.

In general, the Elasticity Coefficient curve of the wealth grade in Shenzhen accords to the form of the environmental Kuznets curve.

\section{Conclusions and Discussion}

In the cultivated area is changing social and economic drivers in the study, and introduces the field of environmental studies, and selected STIRPAT model of socio-economic indicators for the analysis. In Shenzhen City through the empirical study and found that STIRPAT model can be a better fit cultivated area and socio-economic indicators, reflecting the relationship between the per capita GDP, industrial structure, level of development and urbanization of agricultural land area, such as the impact of changes.

In accordance with the model and associated the STIRPAT analysis in 1979, and can be seen during the 2008, and a variety of social factors affect the Shenzhen cultivated land area, and the changes do not have that element of the show the lead driver role, showing that the arable land change drivers with the complexity and comprehensiveness (Zhao, 2006).

From each of the driven element to look at: industrial restructuring to improve land use intensity levels and thus reduce the curb area of agricultural land, and therefore should be to continue to increase the readjustment of the industrial structure, urbanization and the increase in the rate is not very good ease of use of land for the development of the city, must be to take some land, but to make a reasonable plan; GDP per capita is rich, with the growth of the cultivated land in a similar environment changes between Kuznets curve, that the city's land use structure has been in the reform and opening up a period of more than 30 years in both urban and rural areas, and convert the urbanization of the high-speed development stage. The urban economic level reaches a certain level, the non-agricultural land speed up construction projects can be alleviated.

Built on a model-based analysis, combined with the practical development of Shenzhen, from the following aspects of the protection to be arable land resources: co-ordination arrangements with cities and urban planning scientific indicators to use structure; the expansion of the urban space, meaning potential excavation efforts must be to further enhance land use; the degree of concentration to continue to adjust the industrial structure and explore the urbanization patterns. In addition, it must be pointed out that the study of the human factor, and drive the drive model is only applicable to the study area, and try again for other regions, in particular, a relatively slow urbanization of the area is that it applies also to be the case study of the validation and refinement (Su WeizhongYang, \& Gu Chaolin, 2007).

\section{References}

Yinying Cai, \& Anlu Zhang. (2005). Analysis of relationship between loss of cultivated land resource and economic development. China Population Resources and the Environment.

Chertow, M. R. (2000). The IPAT equation and its variants: changing views of technology and environmental impact. Journal of Industrial Ecology.

Floating Chen, \& Gang Chen. (2001). And human driving forces of land use change in urban fringe research. Natural Resources Journal. http://dx.doi.org/10.1023/A:1011581414877

Jianmin Hu, \& Yishao Shi. (2008). Applicability on the cultivated land Kuznets curve of China. Resources and Environment in the Yangtze Basin.

Haixia Zheng, \& Tong Ju Son. (2007). Spatio-temporal change and driving forces of cultivated land resources in developed areas: an empirical study. Journal of Agricultural Engineering.

Kang-Lin. (2006). STIRPAT model-based analysis of China's environmental pressures to 1952-2003 the time-difference-of-year energy consumption, for example. Natural Resources Journal.

Lurgi. (1999). Development and the protection of cultivated land resources in China and the problem of food security. Resource Science.

Xiaowen Li. (2003). Dynamic change of cultivated land in the lower reaches of the Yangtze River in recent 10 years features. Natural Resources Journal.

Rosa, E. A., York, R., \& Dietz, T. (2004). Tracking the anthropogenic drivers of ecological impacts. AMBIO.

Su WeizhongYang, \& Gu Chaolin. (2007). Grade evaluation of cultivated land protection in Suzhou. Natural Resources Journal. 
Vanci, \& Zhao Shidong. (2001). Analysis of driving force system of land-use changes. Resource Science.

Wu Ye, Yang Guishan, Wan Rongrong, and so on. (2007). Suzhou city difference analysis of socio-economic driving forces of the cultivated land area change in. Geography and Geographic Information Science.

Zhongmin Xu, \& Guodong Cheng. (2005). China's population and wealth of effects on the environment. Glaciology and Cryopedology.

Zhongmin Xu, Xinhua Wang, and so on. (2006). 2000 population, affluence and technology of Chinese water footprint impact. ACTA Ecologica Sinica.

Zhongmin Xu, \& Guodong Cheng. (2005). Effects of China's population and affluence on environment . Glaciology and Cryopedology.

Guishan Yang. (2001). Process of Yangtze River Delta nearly 50 years of cultivated land quantity change and driving mechanism of it. Natural Resources Journal.

Guishan Yang. (2002). Analysis of dynamic balance of total amount of cultivated land quantity change in trend and prospect in the Yangtze Delta. Journal of Natural Resources.

Guishan Yang. (2004). Land-use/cover change and regional economic. Acta Geographica Sinica.

York, R., Rosa, E. A., \& Dietz, T. (2003). STIRPAT, IPAT and ImPACT: analytic tools for unpacking the driving forces of environmental impacts. Ecological Economic. http://dx.doi.org/10.1016/S0921-8009(03)00188-5

Changcheng Ye, \& Yuxiang Dong. (2007). Guangzhou study on the relationship between industrial structure and change of cultivated. China Agricultural Resources and Regional Planning.

Anlu Zhang. (1999). Urban and rural ecological economic zone of mechanism and system innovation of rural-urban land conversion. China's Rural Economy.

Bingzhong Zhou. (2003). Mathematical study on cultivated land use change and its driving mechanism in Jiangsu Province. Journal of Soil.

Yonghua Zhao. (2006). Change and driving forces of cultivated land in Wenchuan County in the upper reaches of the minjiang River. Journal of Agricultural Engineering. 